\title{
Radiation Shielding Analysis and Design of tof PET-CT Facility at Institute of Nuclear Medical Physics under Bangladesh Atomic Energy Commission, Bangladesh
}

\author{
M. F. Uddin'1, R. Khatun'2, S. Akter ${ }^{2}$, H. M. Jamil'1, A. N. Monika1, M. A. Rahaman'1, R. P. Das', \\ R. A. Sharmin', M. M. Rahman'2, M. M. Ahasan'1 \\ ${ }^{1}$ Institute of Nuclear Medical Physics, AERE, Savar, Dhaka, Bangladesh \\ ${ }^{2}$ Atomic Energy Centre, Dhaka, Bangladesh \\ Email: sazid_cu07@yahoo.com
}

How to cite this paper: Uddin, M.F., Khatun, R., Akter, S., Jamil, H.M., Monika, A.N., Rahaman, M.A., Das, R.P., Sharmin, R.A., Rahman, M.M. and Ahasan, M.M. (2019) Radiation Shielding Analysis and Design of tof PET-CT Facility at Institute of Nuclear Medical Physics under Bangladesh Atomic Energy Commission, Bangladesh. International Journal of Medical Physics, Clinical Engineering and Radiation Oncology, 8, 1-8.

https://doi.org/10.4236/ijmpcero.2019.8100 1

Received: November 8, 2018

Accepted: January 18, 2019

Published: January 21, 2019

Copyright $\odot 2019$ by author(s) and Scientific Research Publishing Inc. This work is licensed under the Creative Commons Attribution International License (CC BY 4.0).

http://creativecommons.org/licenses/by/4.0/

\begin{abstract}
High resolution (4 $\mathrm{mm}$ ) tof PET-CT (positron emission tomography-computed tomography) from Philips of model Ingenuity TF is newly installed at Institute of Nuclear Medical Physics (INMP). 128 slice CT component incorporated with PET provides comparatively lower dose than the $511 \mathrm{keV}$ annihilation photons associated with positron decay from PET scan. So, for designing shielding in our PET-CT facility, only $511 \mathrm{keV}$ annihilation photons energy has been considered. The main objective of this paper is to show what measures have been taken to protect patients, occupational workers as well as environment from PET-CT radiation hazard through a cost effective design that satisfy the national regulatory demand. In this paper, AAPM (American Associations of Physicists in Medicine) Task group 108 analysis for PET and PET-CT shielding requirements is followed for our PET-CT facility shielding design. From theoretical calculation as shielding requirement, $1.1 \mathrm{~cm} \mathrm{~Pb}$ thickness or, $13 \mathrm{~cm}$ concrete thicknesses are found. Practically, all walls and ceiling are of $30.48 \mathrm{~cm}$ ( $1 \mathrm{foot}$ ) thick made of concrete with density $2.35 \mathrm{gcm}^{-3}$ for more safety. As x-ray from CT is not taken into account for shielding analysis, Bangladesh Atomic Energy Commission (BAEC) conducted an extensive radiation survey at controlled, supervised and public area for CT. The report that is found meets the national regulatory requirements.
\end{abstract}

\section{Keywords}

Radiation Protection, PET-CT, Shielding, FDG 


\section{Introduction}

Bangladesh is a developing country and is now facing many challenges, especially in health sector. Government has given the priority in cancer diagnosis and management due to the current trend of cancer disease in this region. Under this consideration, nuclear tof PET-CT (time of flight positron emission tomography-computed tomography) machine for imaging purpose is newly installed at Institute of Nuclear Medical Physics (INMP) under Bangladesh Atomic Energy Commission (BAEC). Here, CT part is incorporated with PET to get fused image. This machine can diagnose cancer at molecular level. PET image resolution is very high ( $4 \mathrm{~mm}$ ) imported from Philips (USA) of model Ingenuity TF; timing resolution and coincidence window are 600 ps and 5 ns respectively. In this machine, LYSO $\left(\mathrm{Lu}_{1.8} \mathrm{Y}_{0.2} \mathrm{SiO}_{5}: \mathrm{Ce}\right)$ crystals are used. The number of crystal detectors and PMTs are 28,336 and 420. PET-CT is a sophisticated device, so shielding pattern is totally different from other imaging device. 128 slice CT $(80-140 \mathrm{kV})$ component incorporated with PET, gives comparatively lower dose than the 511 $\mathrm{keV}$ annihilation photons dose associated with positron decay from PET scan [1]. Designing shielding in PET-CT facility, only $511 \mathrm{keV}$ annihilation photons energy has been considered. Actually, CT technology is used for attenuation correction in surrounding organ of region of interest and help in the exact anatomical localization of the molecular changes diagnosed by PET [2]. The National Council on Radiation Protection and Measurements (NCRP) defines "shields" as a physical entity interposed between a source of ionizing radiation and an object to be protected so that the radiation level at the position of that object will be reduced [3]. Floors and ceilings, adjacent walls as well as door are considered to be calculation as shielding. As Low As Reasonably Achievable (ALARA) principle is used in exposure to radiation and other occupational health risks [4]. During PET-CT shielding calculation, the factors are taken into account are source of radiation, amount of activity, decay of activity, number of patient per day, distance, shielding material and occupancy factor etc. A lot of methods have been developed in this calculation but in all cases above factors are considered.

\section{FDG Radionuclide}

The radiotracer used for PET scan is fluoro-2-deoxyglucose (FDG). FDG is labeled with $\mathrm{F}^{18}$, whose half life is only $109 \mathrm{~min}$. Before scanning, typically 5 to $10 \mathrm{mCi}(185-370 \mathrm{MBq})$ of $\mathrm{F}^{18}$-FDG is injected rapidly into a saline drip running into a vein of a patient who has been fasting for at least 6 hours. After about an hour of injection, patient is undergone for PET scan. And it takes about 20 to 30 minutes. FDG chemical structure and positron annihilation process are shown in Figure 1 and Figure 2. The above mentioned administered activity is common practice in Bangladesh. But for shielding calculation, administered activity is considered to be higher.

\section{Regulatory Limit}

Maximum permissible dose per year (P) for radiation worker is $20 \mathrm{mSv}$ (averaged over five consecutive years) and $50 \mathrm{mSv}$ in a single year. For ALARA 


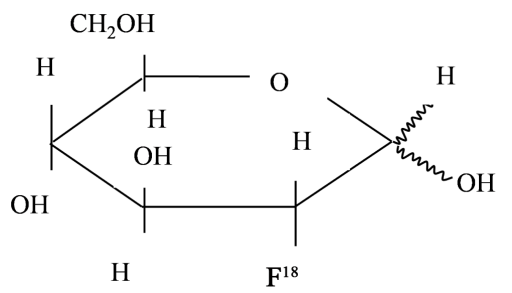

Figure 1. FDG chemical structure containing glucose and $\mathrm{F}^{18}$.

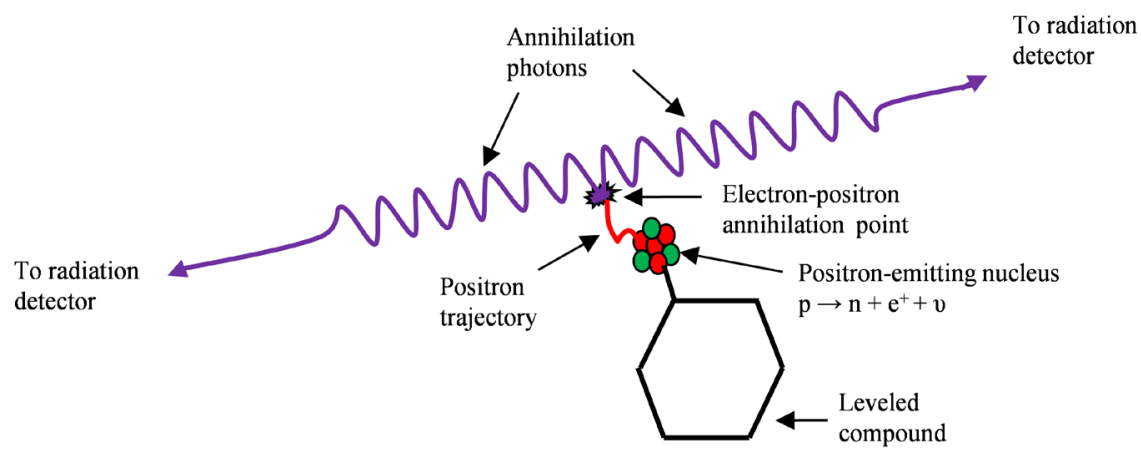

Figure 2. Two anti-parallel $511 \mathrm{keV}$ photons production in nuclear annihilation process. These $511 \mathrm{keV}$ photons are used for PET-CT facility shielding calculation. True coincidence of photons from number of annihilation events detected in PET machine are used for image formation.

principle it is taken as $1 / 10$ of maximum value. So, $\mathrm{P}$ value is $5 \mathrm{mSv} / \mathrm{yr}$. But, according to Bangladesh Atomic Energy Regulatory Act 2012 and Nuclear Safety \& Radiation Control Rules 1997, P value should be $0.1 \mathrm{mSv} / \mathrm{yr}$ for shielding calculation in consideration with public dose. In controlled area, dose rate for radiation worker is $10 \mu \mathrm{S} \mathrm{v} \cdot \mathrm{hr}^{-1}$ and $0.50 \mu \mathrm{Sv} \cdot \mathrm{hr}^{-1}$ for that of uncontrolled area. Layout of PET-CT facility at INMP is shown in Figure 3. The aim of this paper is what measures have been taken to protect patients, occupational workers as well as environment from PET-CT radiation hazard.

\section{Methods}

\subsection{Shielding Analysis}

$\mathrm{F}^{18}$-FDG administered dose varies from patient to patient. Bangladeshi people are small in size compared with other country patients. It depends on patient mass, uptake time and the acquisition mode etc. [1]. It is assumed that all photons emitted from patient are $511 \mathrm{keV}$. Then dose rate $D^{\bullet}$ at distance $r(\mathrm{~m})$ from activity $A(\mathrm{MBq})$ is

$$
D^{\bullet}=\frac{\Gamma A}{r^{2}}
$$

where, $\Gamma \rightarrow$ Effective dose rate constant.

Since the patient itself becomes the radioactive source after the radiopharmaceutical has been administered, one has to consider the entire time that the subject remains in the clinic [1]. 


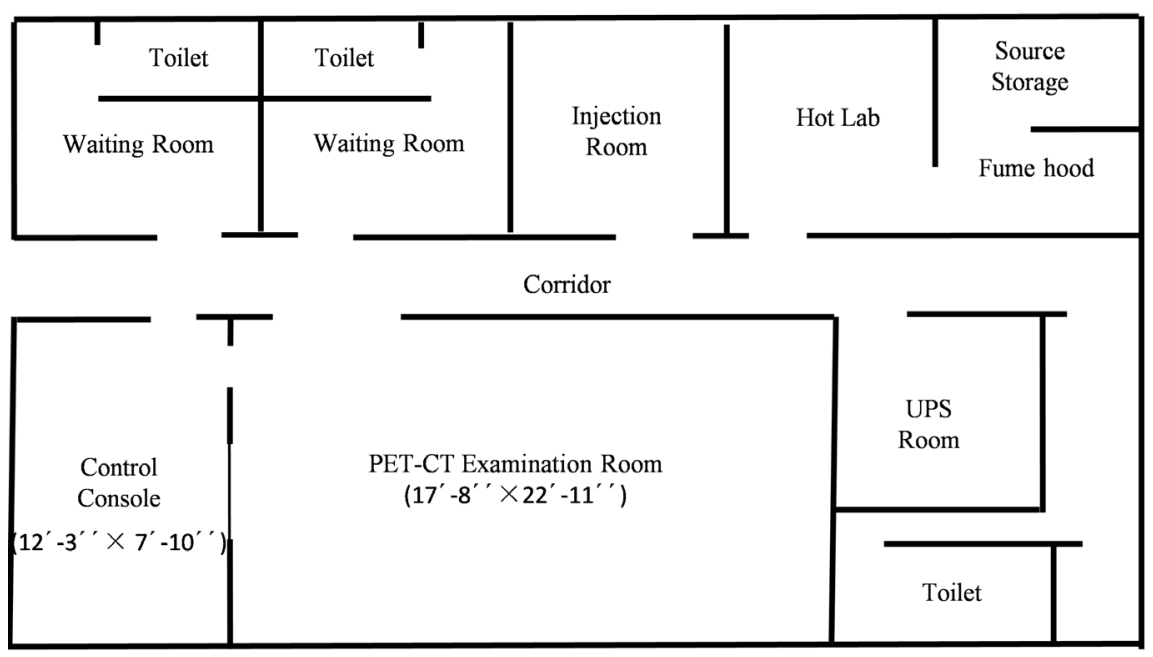

Figure 3. Layout of PET-CT facility showing examination room, control console and hot lab etc. separately at INMP. Shielding calculations are done of these rooms, where all rooms are considered to be parallel to examination room.

The dose $D$, accumulated over time $t$ is

$$
D=1.44 \times D^{\bullet} \times T_{1 / 2} \times\left(1-\mathrm{e}^{-\frac{0.693 \times t}{T_{1 / 2}}}\right)
$$

and track decay of activity from moment-to-moment.

$$
A(t)=A_{0} \times\left(\mathrm{e}^{-\frac{0.693 \times t}{T_{1 / 2}}}\right)
$$

Corresponding lead, concrete and iron thickness for broad beam transmission factors $B$ at $511 \mathrm{keV}$ is obtained from the Table 1 [1].

Another alternative way to measure thickness value is

$$
I=B_{0} \times I_{0} \mathrm{e}^{-\mu t}
$$

or

$$
\frac{I}{I_{0}}=\mathrm{e}^{-\ln 2 / \mathrm{HVL}}
$$

where, $\mu$ is attenuation co-efficient whose value is $1.92 \mathrm{~cm}^{-1}$ for lead in case of broad beam of energy $511 \mathrm{keV}$ [5]. $B_{0}$ is buildup factor. The value of $B_{0}$ increases with the increase of the thickness of the shielding material. The mean free path of $511 \mathrm{keV}$ photon in air is near about 100 meter and so it's attenuation in air is considered to be zero [6]. Equation (4) is used for shielding calculation if broad beam transmission data shown in Table 1 is not available. HVL values of water, concrete and lead are $7.58 \mathrm{~cm}, 3.42 \mathrm{~cm}$ and $0.40 \mathrm{~cm}$ respectively for $511 \mathrm{keV}$ photons [7].

\subsection{Concrete Wall Shielding}

AAPM Task Group 108 recommends a realistic effective dose rate constant $\Gamma$ 
Table 1. Broad beam transmission factors at $511 \mathrm{keV}$ in lead, concrete and iron.

\begin{tabular}{|c|c|c|c|}
\hline \multirow{2}{*}{ Thickness ${ }^{\mathrm{a}, \mathrm{b}}$} & \multicolumn{3}{|c|}{ Transmission factors } \\
\hline & Lead & Concrete & Iron \\
\hline 0 & 1.0000 & 1.0000 & 1.0000 \\
\hline 1 & 0.8912 & 0.9583 & 0.7484 \\
\hline 2 & 0.7873 & 0.9088 & 0.5325 \\
\hline 3 & 0.6905 & 0.8519 & 0.3614 \\
\hline 4 & 0.6021 & 0.7889 & 0.2353 \\
\hline 5 & 0.5227 & 0.7218 & 0.1479 \\
\hline 6 & 0.4522 & 0.6528 & 0.0905 \\
\hline 7 & 0.3903 & 0.5842 & 0.0542 \\
\hline 8 & 0.3362 & 0.5180 & 0.0319 \\
\hline 9 & 0.2892 & 0.4558 & 0.0186 \\
\hline 10 & 0.2485 & 0.3987 & 0.0107 \\
\hline 12 & 0.1831 & 0.3008 & 0.0035 \\
\hline 14 & 0.1347 & 0.2243 & 0.0011 \\
\hline 16 & 0.0990 & 0.1662 & 0.0004 \\
\hline 18 & 0.0728 & 0.1227 & 0.0001 \\
\hline 20 & 0.0535 & 0.0904 & \\
\hline 25 & 0.0247 & 0.0419 & \\
\hline 30 & 0.0114 & 0.0194 & \\
\hline
\end{tabular}

${ }^{a}$ Thickness in mm for lead. ${ }^{\mathrm{b}}$ Thickness in $\mathrm{cm}$ for concrete and iron.

is $0.092 \mu \mathrm{Sv} \cdot \mathrm{m}^{2} \cdot \mathrm{MBq}^{-1} \cdot \mathrm{hr}^{-1}$ for $\mathrm{F}^{18}$ in patient [1]. Incubation time in a quiet isolated room of FDG patient is 45 minutes. It is assumed that the patient is injected with $555 \mathrm{MBq} \mathrm{F}^{18}$ [1]. Using Equation (3), after 45 minutes, activity $A(t)$ is found to be $420 \mathrm{MBq}$. Normally, patient scanning time is $30-60$ minutes. So, $t$ value is taken as 45 minutes. For fully occupied uncontrolled area,

$$
P / T=1 \mathrm{mSv} \cdot \mathrm{yr}^{-1} / 1=1 \mathrm{mSv} \cdot \mathrm{yr}^{-1}
$$

where, occupancy factor $T=1[1]$.

At $3.5 \mathrm{~m}$ distance, with initially $420 \mathrm{MBq}$ in patient, the dose rate is

$$
D^{\bullet}=\frac{\Gamma A}{r^{2}}=\frac{0.092 \mu \mathrm{Sv} \cdot \mathrm{m}^{2} / \mathrm{MBq} \cdot \mathrm{h} \times 420 \mathrm{MBq}}{(3.5 \mathrm{~m})^{2}}=0.0032 \mathrm{mSv} / \mathrm{hr}
$$

Assuming 40 PET patients per week and 2080 patients per year, the annual dose $D$ in the office for a $45 \mathrm{~min}$ scan is then

$$
\begin{aligned}
D & =2080 \mathrm{pat} / \mathrm{yr} \times 1.44 \times 0.0032 \mathrm{mSv} / \mathrm{hr} \times 1.83 \mathrm{hr} \times\left(1-\mathrm{e}^{-\frac{0.693}{1.83 h} \times 0.75 \mathrm{hr}}\right) \\
& =4.3 \mathrm{mSv} / \mathrm{yr}
\end{aligned}
$$

So, broad beam transmission factors $B$ at $511 \mathrm{keV}$ is 


$$
B=1 \mathrm{mSv} \cdot \mathrm{yr}^{-1} / 4.3 \mathrm{mSv} \cdot \mathrm{yr}^{-1}=0.23
$$

Concrete wall shielding thickness for $B$ value 0.23 is found to be from Table 1 [1].

\subsection{Glass Window Shielding}

There is a lead equivalent glass window in between control console and PET-CT room. This glass thickness is calculated from Table 1 for $B$ value 0.23 . Considering the buildup factor, an alternative approach can also be in case of lead glass using Equation (4). In lead, $B_{0}$ value is assumed to be 1 [8]. So from Equation (4), glass thickness $t$ can be found as follows.

$$
\begin{aligned}
& B=\frac{I}{I_{0}}=B_{0} \times \mathrm{e}^{-\mu t}=0.23, \ln 0.23=-\mu t, \\
& t=\frac{-1.46}{-1.92}=0.76 \mathrm{~cm}=7.6 \mathrm{~mm}, t \approx 8 \mathrm{~mm}
\end{aligned}
$$

where, $\mu=1.92 \mathrm{~cm}^{-1}$ as mentioned earlier [5].

\section{Results}

From theoretical calculation as shielding requirement for our PET-CT facility, $11 \mathrm{~mm} \mathrm{~Pb}$ thickness or, $13 \mathrm{~cm}$ concrete thickness are found shown in Table 2 . Sometimes, theoretical calculations do not meet the practical demand. This may be due to the improper concrete mixing ratio. Though Bangladesh Atomic Energy Regulatory Authority (BAERA) recommends $\mathrm{P}$ should be one tenth of public dose for quality assurance but in this calculation public dose (i.e., $\mathrm{P}=1$ $\mathrm{mSv} / \mathrm{yr}$ ) is used. The formula in Equation (4) is used in shielding calculation only for lead glass not for concrete walls. In this study, only imaging room wall and lead glass shielding requirement have been calculated and all other rooms such as uptake room, hot lab etc. are considered to be parallel of examination room. All walls and ceiling are made of $30.48 \mathrm{~cm}$ (1 foot) thick concrete with density $2.35 \mathrm{~g} \cdot \mathrm{cm}^{-3}$ for more safety. Lead equivalent glass of $10 \mathrm{~mm}$ thickness is used for windowing purpose in between imaging and control room. But in calculation, $11 \mathrm{~mm}$ and $8 \mathrm{~mm}$ thickness are found considering transmission and buildup factor respectively. CT portion is ignored in this calculation, because HVL for the CT $\mathrm{x}$-rays is so much smaller than that for $511 \mathrm{keV}$ photons [1]. Entrance wooden door is sandwiched with $4 \mathrm{~mm}$ thick lead. Control console and

\begin{tabular}{|c|c|c|c|c|}
\hline S1. No. & Parameter name & Technique used & Thickness value & Designed value \\
\hline \multirow{3}{*}{1} & \multirow{3}{*}{ Concrete barrier } & Transmission factor & $13 \mathrm{~cm}$ & \multirow{3}{*}{$30.48 \mathrm{~cm}$} \\
\hline & & & & \\
\hline & & Buildup factor & - & \\
\hline \multirow{3}{*}{2} & \multirow{3}{*}{ Lead equivalent glass } & Transmission factor & $11 \mathrm{~mm}$ & \multirow{3}{*}{$10 \mathrm{~mm}$} \\
\hline & & & & \\
\hline & & Buildup factor & $08 \mathrm{~mm}$ & \\
\hline
\end{tabular}
corridor are considered to be controlled area and radiation level should be below

Table 2. Required thickness values for PET-CT facility design. 
$10 \mu \mathrm{Sv} / \mathrm{hr}$ according to BAERA regulations. From measurement, radiation levels are found to be near background level.

\section{Discussions}

In Equation (4), $B_{0}$ is not needed if the beam is well collimated. In case of PET-CT shielding design, comparatively large thickness is required. So beam geometry is poor and considered to be broad-beam resulting significant number of scattered and back scattered radiation. Therefore, buildup factor $B_{0}$ is applicable [5]. But using buildup factor, thickness value is not calculated for concrete barrier. In addition with concrete shield design, there are some devices such as syringe shielding, lead apron etc. are also considered as shielding device. Syringe shield reduces the dose rate $25 \%$ in hands and fingers in case of PET substances. In Nuclear Medicine, where there are ambient radiation are higher than radiography, lead apron is recommended. It is effective in $\mathrm{Tc}^{99 \mathrm{~m}}(140 \mathrm{keV})$ scan. Because $0.25 \mathrm{~mm}$ and $0.50 \mathrm{~mm}$ lead apron reduce the dose rate $59 \%$ and $76 \%$ respectively. For higher energies, such as $\mathrm{F}^{18}(511 \mathrm{keV})$, lead apron is in little use. On the other hand, in case of CT, mean photon energy is $1 / 3$ of the tube voltage. Our CT tube voltage is in between $80-140 \mathrm{kV}$, which generate average (26.67 46.67) $\mathrm{keV}$ photons [9]. So it is a matter of question, either lead apron is necessary or not in case of CT. Health Physics Division of BAEC conducted an extensive radiation survey, especially for CT portion of tof PET-CT facility at INMP and found the doses ranged from $0.07-1.58 \mu \mathrm{Sv} / \mathrm{hr}$ and $0.30-1.21 \mathrm{~Bq} / \mathrm{cm}^{2}$ for $\mathrm{x}$-ray radiation dose rate and beta surface activity respectively.

\section{Conclusion}

PET-CT machine is highly sophisticated imaging device. So the shielding calculation for PET-CT facility is completely different from those of other diagnostic and therapeutic facilities. In this case, the patient itself continuously emits high energy annihilation photon radiation during the whole procedure. In our facility, all shielding walls are made of concrete with thickness more than double of calculated value. The main entrance door is made of $4 \mathrm{~mm}$ thick lead sheet which is sandwiched in between two layer of wood. During the machine in operation, radiation survey reports meet our regulatory requirements.

\section{Conflicts of Interest}

The authors declare no conflicts of interest regarding the publication of this paper.

\section{References}

[1] Madsen, M.T., et al. (2006) AAPM Task Group 108: PET and PET/CT Shielding. Medical Physics, 33, 4-15. https://doi.org/10.1118/1.2135911

[2] Santana, P.C., Oliveira, P.M.C., Mamede, M., Silveira, M.C., Aguiar, P., Real, R.V. and Silva, T.A. (2015) Ambient Radiation Levels in Positron Emission Tomography/Computed Tomography (PET/CT) Imaging Center. Radiologia Brasileira, 48, 
21-25. https://doi.org/10.1590/0100-3984.2013.1821

[3] Uddin, M.F., Ahasan, M.M., Khatun, R., Akter, S., Jamil, H.M., Monika, A.N. and Rahman, M.A. (2017) Shielding Design Basis and Its Calculation of High Energy Medical Linac Installed in Bangladesh Atomic Energy Commission, Bangladesh. Universal Journal of Medical Science, 5, 27-31.

[4] Ivanova, S. and Artinyan, A. (2015) Calculations and Analysis of the Radiation Protection of PET/CT Center. BgNS Transactions, 20, 54-57.

[5] Cember, H. and Johnson, T.E. (2009) Introduction to Health Physics: External Radiation Safety. 4th Edition, The McGraw-Hill Companies, New York.

[6] Mollah, A.S. and Muraduzzaman, S.M. (2011) Calculation of Shielding and Radiation Doses for Pet/Ct Nuclear Medicine Facility. Proceedings of the International Conference on Mathematics and Computational Methods Applied to Nuclear Science and Engineering, Rio de Janeiro, 8-12 May 2011.

[7] Kearfott, K.J., Carey, J.E., Clemenshaw, M.N. and Faulkner, D.B. (1992) Radiation Protection Design for a Clinical Positron Emission Tomography Imaging Suite. Health Physics, 63, 581-589. https://doi.org/10.1097/00004032-199211000-00012

[8] Saha, G.B. (2010) Basics of PET Imaging Physics, Chemistry, and Regulations. 2nd Edition, Springer Science, New York. https://doi.org/10.1007/978-1-4419-0805-6

[9] Mattsson, S. and Hoeschen, C. (2013) Radiation Protection in Nuclear Medicine. Springer, New York. https://doi.org/10.1007/978-3-642-31167-3 